\title{
Comparative Study on Oil Recovery Enhancement by WAG Injection Technique in a Fractured Oil Reservoir in the Southwest of Iran
}

\section{Hajnajafi Reza ${ }^{1}$, Amid Arman ${ }^{2}$ and Hajnajafi Ghazal ${ }^{3}$}

${ }^{1}$ Department of Petroleum Engineering, University of New South Wales, Sydney, Australia

${ }^{2}$ Department of Environmental Management HSE, Tehran North branch of Islamic Azad University, Tehran, Iran

${ }^{3}$ Department of Geology, University of Science and Research of Islamic azad university, Tehran, Iran

\begin{abstract}
Water alternating gas injection (WAG) and simultaneous water and gas injection (SWAG) are injection techniques used to enhance oil recovery. Gas injection is today regarded as the second method for increasing oil recovery. While very little oil remains in the areas swept by gas, the amount of volumetric displacement by injected gas has always drawn much concern. This is due to high mobility ratio of the gas injected to reservoir oil. To solve this problem, WAG and SWAG injection techniques are used to control fluid flow profile. High microscopic displacement efficiency of gas (in whole scale) and high volumetric displacement efficiency of water (in microscopic scale) considerably increases oil recovery in the front space of water. In this paper, we investigate various WAG injection methods using Eclipse and compare the results to determine the best injection scenario for the reservoir under study.
\end{abstract}

Keywords: Oil recovery enhancement; Fractured reservoirs; Simulation; SWAG injection technique; WAG injection technique

\section{Introduction}

SWAG is a modern technique used to recover oil. In this method, a mass of water and gas is simultaneously injected into the reservoir. The most important advantage of this technique over WAG is better control of gas mobility thanks to injection of a specified quantity of water. This method was first executed at Seeligson field in the southwest of Texas in 1963. SWAG injection technique considerably reduces costs by: A) eliminating the separation between water and gas during injection; B) eliminating changes in operation equipment; and C) reducing the costs incurred by GOR [1]. Simulation studies indicate that SWAG injection with 1:1 ratio increases oil-in-place production by $5 \%$ compared with $4.5 \%$ increase offered by WAG injection method [1]. In the next paragraphs, we review the history of WAG and SWAG processes.

Surgnchev conducted a comparative study on WAG, FAWAG and SWAG injection methods using a three-dimensional model [2]. Permeability of the model was $220 \mathrm{md}$ in the upper part and 2-20 md in the lower part. In this model, vertical and horizontal wells were designed for production and injection, as illustrated in Figure 1. Simulation results indicated an oil-in-place recovery of $51 \%$ after injection, with oil being mostly recovered from the small section in upper part of the model. In SSWAG model, gas was injected to the upper part with thickness of $100 \mathrm{ft}$ and water was injected to the lower part with thickness of $40 \mathrm{ft}$. Moreover, WAG and SSWAG were compared as a third method for increasing oil recovery. According to the results, recovery efficiency increased from $26.6 \%$ to $31.1 \%$ [2]. Esmaiel studied water-to-gas ratio in WAG injection process and concluded that the increase of water-to-gas ratio will increase oil recovery and water cut rate. So, an optimal ratio must be selected to reduce water cut rate [3].

Meshal algharaib conducted a study on the improved SWAG process parameters. They proposed a model in which gas was injected in the lower part and water was injected in the upper part of the reservoir. In the present study, we investigate WAG and SWAG injection methods. Simulation results indicated that these methods offer better sweeping and recovery efficiency and are more cost effective. This study is limited to determining optimal quantity of water and gas [4]. Mirkalaei studied WAG injection processes to determine optimal injection rate [5].
Jiang studied WAG ratio and reached the following conclusion: determining WAG ratio is one of the important design parameters and considerably affects operational and economic conditions of the project. Optimal WAG ratio is affected by the type of stone wettability. High WAG ratio has the highest impact on oil efficiency in waterfriendly reservoirs and reduces the amount of residual oil [6]. Ghaderi conducted a study on the impact of $\mathrm{CO}_{2}$ miscible injection and WAG injection methods in oil reservoirs with compressed formation [7]. They found that injection of water masses is necessary for reducing fingering impact. Fingering occurs quickly during $\mathrm{CO}_{2}$ injection due to low viscosity of $\mathrm{CO}_{2}$. To delay this, the amount of injected water should be more than $\mathrm{CO}_{2}$. This is especially important in fractured reservoirs. In normal reservoirs and those with very low permeability, however, low viscosity of $\mathrm{CO}_{2}$ may help the process.

In this study, we investigate various WAG injection methods and compare the results in order to determine the best injection scenario for the reservoir under study.

\section{Literature Review}

WAG injection technique was first executed in 1957 in Alberta and produced successful results [8]. Thanks to the advantages of this technique over separated injection methods (e.g. control of relative mobility of displaced and displacing phases, prevention of early fingering in oil production wells, the capability to produce oil from unswept areas, creation of controllable and sustainable progression, and the capability to use operational tools), WAG injection technique

*Corresponding author: Hajnajafi Reza, Department of Petroleum Engineering University of New South Wales, Sydney, Australia, E-mail: rezahajnajafi@gmail.com

Receive December 11, 2015; Accepted January 13, 2016; Published January 23, 2016

Citation: Reza H, Arman A, Ghazal H (2016) Comparative Study on Oil Recovery Enhancement by WAG Injection Technique in a Fractured Oil Reservoir in the Southwest of Iran. J Pet Environ Biotechnol 7: 263. doi:10.4172/21577463.1000263

Copyright: $\odot 2016$ Reza H, et al. This is an open-access article distributed under the terms of the Creative Commons Attribution License, which permits unrestricted use, distribution, and reproduction in any medium, provided the original author and source are credited. 
has become widespread in different points of the world, such as the US, Canada, North Sea, Russia, Turkey and Venezuela, particularly in the past two decades. Researchers have recently studied different aspects of WAG injection method in order to determine the changes in reservoir conditions during injection period.

Cobanoglu designed different scenarios for injection quantity, cycle, and the number of produced and injected wells using ECLIPSE100 Simulator and studied and compared immiscible gas injection and WAG injection methods in Baty Kozluca field in Turkey. According to the results, immiscible gas injection technique considerably increased the field efficiency due to inappropriate mobility ratio. He reported that WAG immiscible injection offers more efficiency compared with immiscible gas injection [9].

Hustod and Klov studied WAG injection method and compared it with water-gas injection method in layers with different permeability levels in the North Sea. They found that water and gas fingering in high-permeability layers and immobility and bad sweeping process in low-permeability layers reduce injection efficiency in these methods. According to their results, WAG injection method prevents gas movement in high-permeability layers, develops a three-phase area in the reservoir, and stabilizes the progression. So, they concluded that WAG injection method offers more efficiency compared to water-gas injection methods [10].

Shi and coworkers studied WAG injection method in Kuparuk field in the north of Alaska for a period of 20 years using field results. They first used gas injection method to increase oil recovery in the field. Due to early fingering and GOR increase, however, they employed WAG injection technique which increased oil production by 120 MMSTB during injection period [11]

Instefjord studied WAG injection method in Gullfaks field for a period of 10 years. According to his results, WAG injection technique increased oil production by 2 MMSTB during injection period. He reported that the execution of WAG injection technique increased displacement efficiency and reduced the percentage of produced water [11]. Trnerr and coworkers, Quale and coworkers, Siri, Skauge and Aarra and Snorer and Quraini have studied WAG injection technique in Seeligsou, Stephansen, Joffer Viking, Snorer and West Sak fields respectively. All of these studies have demonstrated the advantages of WAG injection method over other methods for recovering oil [12]. In the past decade, almost $40 \%$ of gas injection projects throughout the world, such as Canada, Russia, Turkey and Norway, have been executed by WAG injection technique. $80 \%$ of these projects have produced successful results [13].

\section{Research Method}

We investigated various water-gas injection methods using simulations made by Eclipse Simulator and compared the results to determine the best injection scenario for the reservoir. In doing so, we studied oil recovery enhancement using various water-gas injection methods at an under-saturated fractured reservoir in the southwest of Iran. Phase behavior of reservoir fluid was studied by PVTi module of Eclipse 100 (immiscible). After matching the history of reservoir production and pressure data, we simulated various water-gas injection methods based on such parameters as injection quantity and oil production quantity.

\section{Details of matrix and reservoir fracture}

Oil in place is 3.7 MMMbbl, water and oil contact level is $11400 \mathrm{ft}$, and reservoir peak is $9200 \mathrm{ft}$ below the level of free water. Average porosity of fractures is approximately $0.002 \%$ and average permeability of fractures is $1200 \mathrm{md}$. Average porosity of matrix is 0.1 and average horizontal permeability of the matrix is $1 \mathrm{md}$ for all layers.

\section{Details of reservoir oil}

Initial pressure of the reservoir in the depth of $11200 \mathrm{ft}$ is 5600 psi and reservoir temperature is $214 \mathrm{~F}$. Bubble point pressure of the reservoir is $2400 \mathrm{psi}$ and the ratio of dissolved gas to oil is $570 \mathrm{scf} / \mathrm{stb}$. Density and API of reservoir oil are $54 \mathrm{Ib} / \mathrm{ft}^{3}$ and 43 respectively. For reservoir water in the pressure of $5600 \mathrm{psi}$, volumetric coefficient of formation water is $1.3 \mathrm{bbl} / \mathrm{stb}$ and water viscosity is $0.66 \mathrm{cp}$.

\section{Model description}

We simulated dynamic model of the reservoir using Eclipse 100 (immiscible) in three-dimensional and three-phase manner by fullyexplicit equation solving method. For the purpose of simulation, we divided reservoir $\mathrm{A}$ into many blocks. The number of blocks in $\mathrm{X}, \mathrm{Y}$ and $\mathrm{Z}$ is 40,120 and 50 respectively. The first 18 blocks in part $\mathrm{Z}$ belong to matrix and the other 32 blocks belong to fractures. Since the reservoir was fractured, we modeled it with binary porosity.

\section{Optimization of injection wells}

There are six production wells in the reservoir. We consider four of them as production wells and the other two as injection wells. We investigated different scenarios regarding the situation and number of injection wells. The intensity of injection flow in all scenarios was set on $2^{\star} 10^{\wedge} 6 \mathrm{scf} /$ day. The scenario with an injection well in the reservoir peak and a well in lower part of the reservoir was elected as the best scenario for injection. This scenario offers the advantage of late gas penetration into production wells because reservoir slope in this location is fairly good.

\section{Injection method}

In water and gas injection, Buckley and Leverett's theory is equally applicable. In vertical gas and oil flow, however, overlooking the impact of gravity is impossible. So, a variety of equations should be used for minor $f_{a}$ gas flow, depending on whether injection is performed in oil area (flow is assumed to be horizontal) or in gas cap (flow is assumed to be vertical). Therefore, Diffr oil is between time $j$ (reservoir pressure $-P_{j}$ ) and $j+1$ (reservoir pressure $-P_{j}+1$ ), assuming that there is no water penetration. From the equation we can obtain reinjection quantity to maintain full pressure. When pressure remains constant, the numerator of equation is 0 and since recovery is not 0 , the denominator of equation should also be 0 and the equation is indefinite and vague. So, I is obtained. In both injection operations in gas cap and oil area, the first step is to prepare $f_{j}\left(S_{g}\right)$ curve with the assumption of viscosity in saturation [14]. To estimate appropriate minor movement of gas during injection and achieve a harmonious injection progression, the following equation was used [15]. Using cross-injection, an appropriate injection quantity can be applied.

\section{Data Analysis}

We simulated the reservoir in three modes: depletion in normal state, production through gas injection, and production through water injection. In water and gas injection simulation, we defined and executed many scenarios, as shown in Table 1 . We investigated water and gas injection scenarios in two distinct parts, selected the best scenario in each group, and then compared them. To adjust the injected water, which was supplied from sea water, to reservoir and its fluid, and 
Citation: Reza H, Arman A, Ghazal H (2016) Comparative Study on Oil Recovery Enhancement by WAG Injection Technique in a Fractured Oil Reservoir in the Southwest of Iran. J Pet Environ Biotechnol 7: 263. doi:10.4172/2157-7463.1000263

\begin{tabular}{|c|c|}
\hline Symbol & Description \\
\hline WI1 & $4_{p} / 1_{\text {in }}$ \\
\hline WI2 & $4_{p} / 1_{\text {in }}$ \\
\hline WI3 & $4_{p} / 1_{\text {in }}$ \\
\hline WI4 & $23_{\text {pro }}$ \\
\hline WI5 & 5 wat $/ 4_{\mathrm{p}} / 1_{\text {in }}$ \\
\hline $\mathrm{Gl} 1$ & $4_{p} / 1_{\text {in }}$ \\
\hline GI2 & $4_{p} / 1_{\text {in }}$ \\
\hline $\mathrm{GI} 3$ & $4_{p} / 1_{\text {in }}$ \\
\hline GI4 & $2_{\text {in }} 3_{\text {pro }}$ \\
\hline GI5 & $4_{\text {inj }} 1_{\text {pro }}$ \\
\hline WAG1 & 1:1 \\
\hline WAG2 & $1: 2$ \\
\hline WAG3 & $1: 3$ \\
\hline WAG4 & $2: 3$ \\
\hline WAG5 & $3: 4$ \\
\hline WAG cycle 1 & 4 month water, 8 months gas \\
\hline WAG cycle2 & 6 months water, 6 months gas \\
\hline WAG cycle3 & 8 months water, 4 months gas \\
\hline WAG cycle4 & 12 months water, 12 months gas \\
\hline SWAG1 & 1:1 \\
\hline SWAG2 & $1: 2$ \\
\hline SWAG3 & $1: 3$ \\
\hline SWAG4 & $2: 3$ \\
\hline SWAG5 & $3: 4$ \\
\hline M & $\begin{array}{l}\text { Ratio of initial gas cap volume to initial oil } \\
\text { area volume (for injection to oil area without } \\
\text { gas cap } m=0 \text { ) }\end{array}$ \\
\hline 1 & $\begin{array}{l}\text { Produced part of gas which has been re- } \\
\text { injected. }\end{array}$ \\
\hline$R$ & Average GOR between $\mathrm{j}$ and $\mathrm{j}+1$. \\
\hline$f_{g}=1 /\left(1+\left(k_{r o} / k_{r g}\right)\left(\mu_{g} / \mu_{0}\right)\right)$ & Gas injection in oil area \\
\hline \multicolumn{2}{|c|}{$\operatorname{Diffr}=\left(\left(1-r_{j}\right) \operatorname{Diff}\left(B_{o / B_{G}}-R_{S}\right)-(1+m) B_{o} \operatorname{Diff}\left(1 / B_{G}\right)\right) /\left(B_{o / B_{G}}-R_{S}+\bar{R}(1-I)\right.$} \\
\hline \multicolumn{2}{|l|}{$\mathrm{I}=\left(B_{o}+R_{C} * B g /\left(R_{S}+R_{C}\right) B_{g}\right)$} \\
\hline$v_{c}=\left(\rho_{o}-\rho_{G}\right)[K \cdot g \cdot \sin \alpha] /\left(\mu_{o}-\mu_{g}\right)$ & Minor movement of gas \\
\hline$q=v_{c} \cdot A$ & Appropriate quantity for injection \\
\hline
\end{tabular}

Table 1: Research symbols.

to prevent the corrosion, we added some supplements to it. The gas used in this study is methane.

\section{Gas injection}

To achieve the best daily injection quantity in gas injection scenarios, we studied gas injection operation in several fields in which gas injection method had been used to increase recovery, and selected an initial injection quantity based on characteristics and geological information of the reservoir, pressure gradient and depth of the reservoir in injection layer, gradient level of the fracture, and the potentiality of surface installations. To determine the best injection quantity, we frequently changed the quantity and executed the scenarios with each quantity. This way we assessed the sensitivity of reservoir to the increased or decreased quantity and selected the best injection quantity. The best quantity for gas injection was 8 million cubic foot per day for each injection well. For the purpose of better comparison, Figures 1 and 2 illustrate the results obtained from all gas injection scenarios with

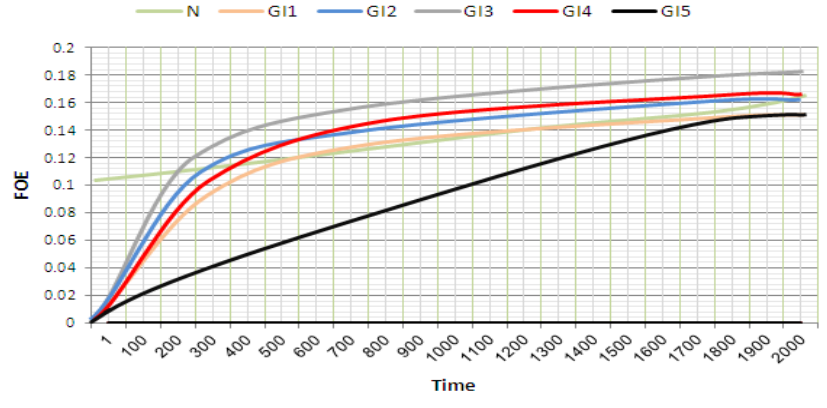

Figure 1: Recovery efficiency obtained from gas injection scenarios.

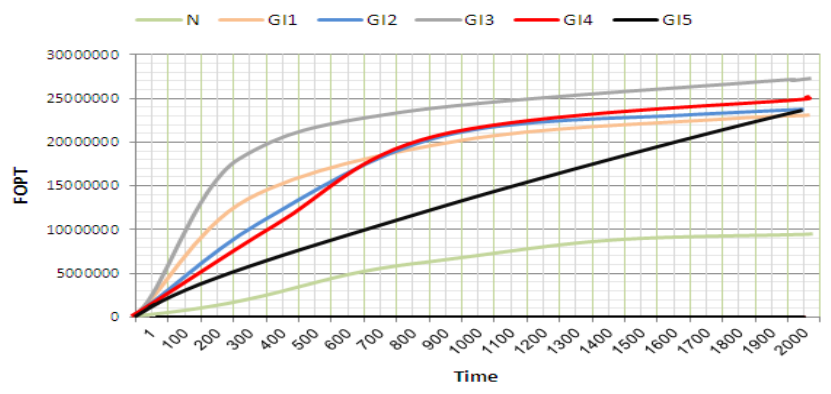

Figure 2: FOPT obtained from gas injection scenarios (stb).

injection rate of 8 million cubic foot per day for each well in different patterns for the intended parameters.

According to the results obtained from gas injection scenarios, the third scenario is the best scenario and offers the best recovery efficiency. In this scenario, injection is made through one well and production is made through four wells defined in the model. Moreover, injection is made in both gas area and the reservoir.

\section{Water injection}

All water injection scenarios were designed like gas injection scenarios, with the only different that injection layers were defined in lower parts of the reservoir, mainly in aquifer. To achieve the best daily injection quantity in water injection scenarios, we studied water injection operation in several fields in which water injection method had been used to increase recovery [13]. First, we selected an initial injection quantity based on characteristics and geological information of the reservoir, pressure gradient and depth of the reservoir in injection layer, gradient level of the fracture, and the potentiality of surface installations. To determine the best injection quantity, we frequently changed injection quantity and executed the scenarios with each quantity. This way we assessed the sensitivity of reservoir to quantity changes and selected the best injection quantity ( 8000 barrels per day). So, we injected 8000 barrels of water to the reservoir each day. Figures 3 and 4 illustrate the results obtained from execution and simulation of eight water injection scenarios with injection rate of 8000 STB/Day.

According to the results obtained from water injection scenarios, the fifth scenario is the best scenario and offers the best recovery efficiency. In this scenario, four water injection and one oil production well have been defined. Water is injected through injection wells (Figure 5). 
Citation: Reza H, Arman A, Ghazal H (2016) Comparative Study on Oil Recovery Enhancement by WAG Injection Technique in a Fractured Oil Reservoir in the Southwest of Iran. J Pet Environ Biotechnol 7: 263. doi:10.4172/2157-7463.1000263

Page 4 of 6

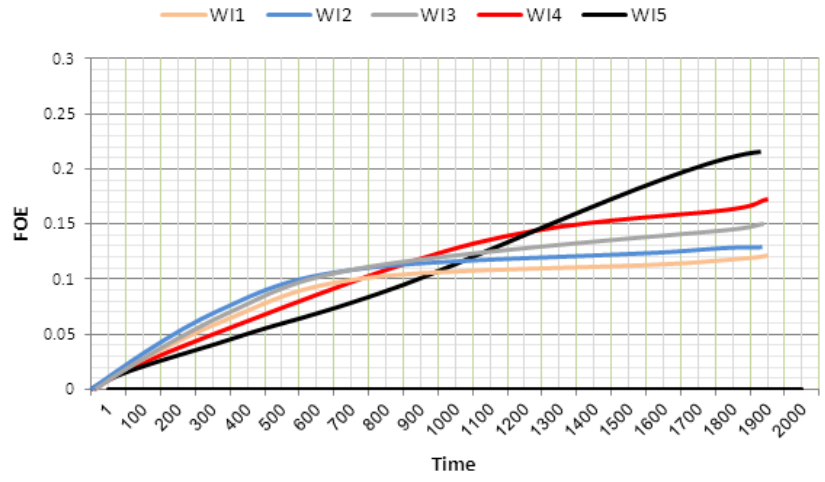

Figure 3: Recovery efficiency obtained from water injection scenarios.

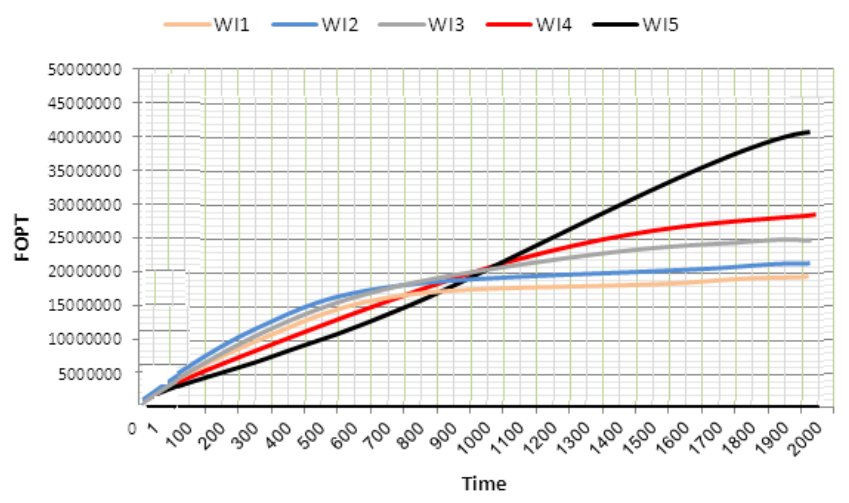

Figure 4: FOPT obtained from water injection scenarios.

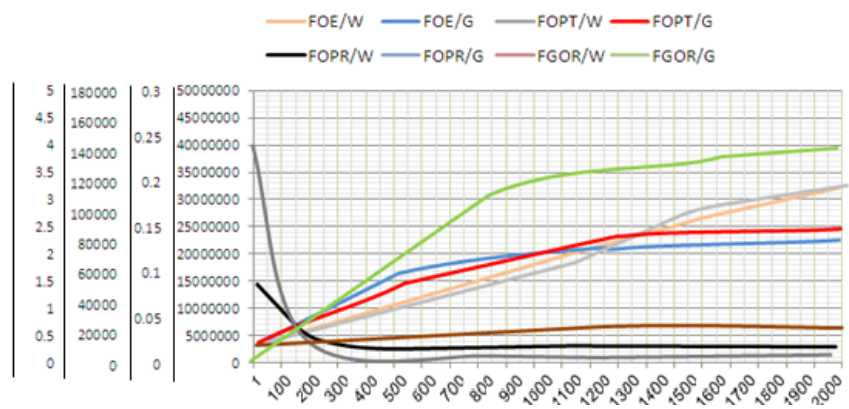

Figure 5: Comparison of the best water and gas injection scenarios.

\section{Comparison of water and gas injection}

We compared the results obtained from the best water and gas injection scenarios in order to determine which injection method offers the best recovery efficiency, field oil production rate and daily production rate, represents lowest gas-to-oil ratio and water cut, maintains reservoir pressure, and is merely based on simulation results without consideration of injection scheme. As mentioned earlier, the best gas injection scenario is the injection from one well and production through four wells with injection rate of 8 million cubic foot per day, and the best water injection scenario is the injection from four wells and production through one well with injection rate of 8,000 barrels per day.

The comparison between the results obtained from the best water injection scenario and the best gas injection scenario indicated that the former produces better results, so water injection scenario was determined as the best scenario.

\section{WAG}

To investigate the impact of this parameter, we set fluid injection volume to be 0.3 time empty space volume of the model. Figures 6 and 7 contain the results. WAG refers to the ratio of injected water to injected gas. If this ratio exceeds its optimal value, water cut increases. If it is less than its optimal value, gas-to-oil ratio (GOR) increases. In SWAG, only the ratio of gas to water is important, with time ratio (cycle) being of no importance because injection is simultaneous. WAG ratio is controlled by gas ability to wet reservoir rock. Immiscible WAG increases the volume of swept oil and improves sweeping efficiency. It also reduces costs through reducing the volume of gas injection to reservoir. Determination and use of optimal WAG ratio is an important parameter in design and greatly affects operational and economic conditions of the project. Further, WAG ratio may be increased following the increase of optimal gas production rate. As you can see, injection ratio of $1: 1$ is the best mode among different injection ratios for the model. Moreover, the more water-to-gas ratio, the earlier gas breakthrough occurs and the more water cut will be $[16,17]$.

To compare the impact of injection cycles, we evaluated four different modes. The results are contained in Figures 8 and 9. In WAG process, each injection cycle is divided into two sub-cycles. In the first sub-cycle, water is injected from injection wells. In the second sub-cycle, gas is injected from injection wells. Generally it is better to inject water to reservoir in the first sub-cycle. If gas is injected in the first sub-cycle, the injected gas quickly reaches the production well because of its high mobility and gas middle-break occurs. If water is injected in the first sub-cycle and gas is injected in the second sub-cycle, water prevents the

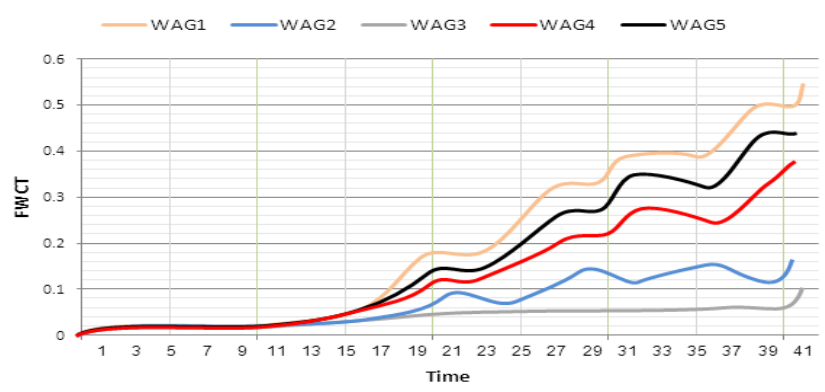

Figure 6: The impact of WAG ratio on water cut rate in WAG process.

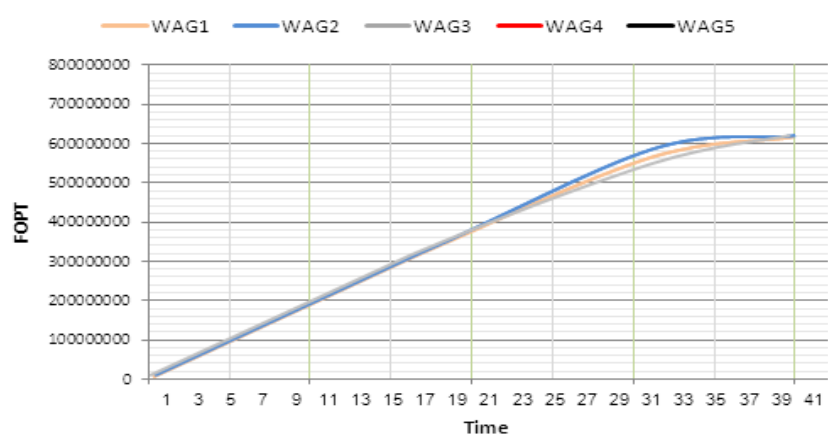

Figure 7: The impact of WAG ratio on oil production rate in WAG process 
Citation: Reza H, Arman A, Ghazal H (2016) Comparative Study on Oil Recovery Enhancement by WAG Injection Technique in a Fractured Oil Reservoir in the Southwest of Iran. J Pet Environ Biotechnol 7: 263. doi:10.4172/2157-7463.1000263

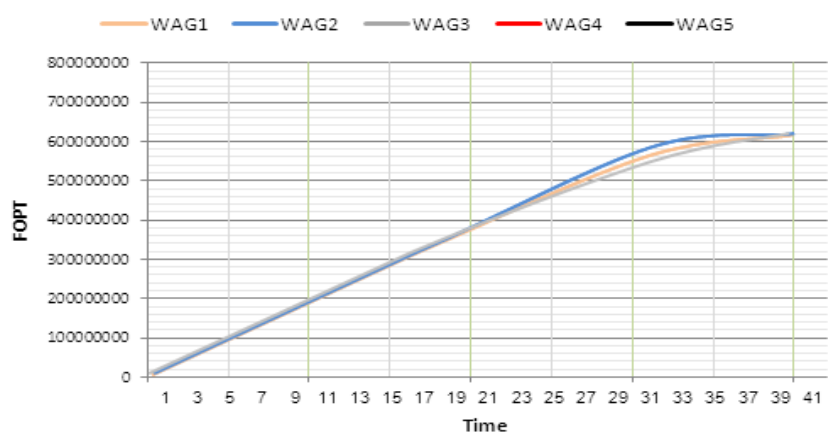

Figure 8: The impact of WAG injection cycle on water cut rate in WAG process.

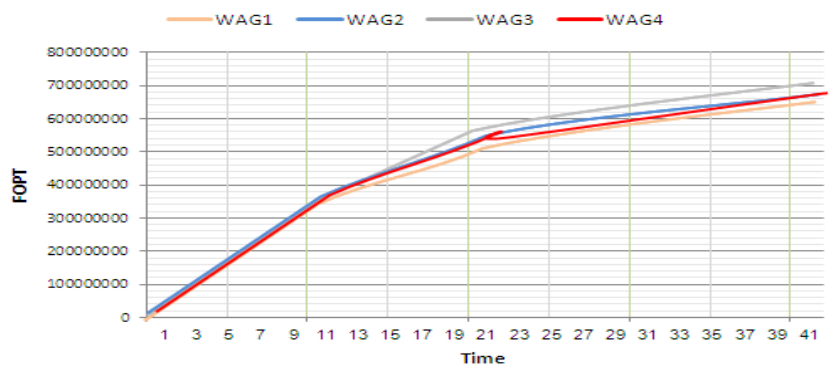

Figure 9: The impact of WAG injection cycle on oil production rate in WAG process.

quick movement of gas and the occurrence of gas breakthrough. This is especially important in cases where reservoir has a high permeability. As you can see, the injection cycle consisting of 12 months of water and 12 months of gas is the optimal cycle for the model.

\section{SWAG process}

To investigate the impact of this parameter, we set fluid injection volume on 0.3 time empty space volume of the model. The results are contained in Figure 10. As you can see, injection ratio of 1:3 is the best mode for the model.

\section{Final comparison}

We compared WAG and SWAG scenarios to determine the optimal one. This comparison was made for injection ratio of 1:1 and injection por volume of 0.3 . The results indicated that SWAG injection scenario was more efficient than WAG injection scenario. In this step, we compared different injection techniques to determine the optimal method. Tables 2 and 3 represent efficiency rates and FOPT of the methods in question. As you can see, SSWAG offers the highest efficiency. So, it could be said that displacement efficiency in this method is better than in other injection methods because of the type of injection and the enhanced efficiency of gas and water injection in the movement and displacement of reservoir oil toward production well. As you can see, SSWAG offers more FOPT compared with other injection methods.

\section{Comparison of WAG and IWAG methods}

Since WAG injection includes different water and gas injection methods, it is necessary to compare it with IWAG in order to determine an optimal method for increasing oil recovery and enhancing production efficiency. To make a proper comparison between the above methods, we not only investigated WAG injection method but also designed and studied a variety of water and gas injection techniques. From each method, we

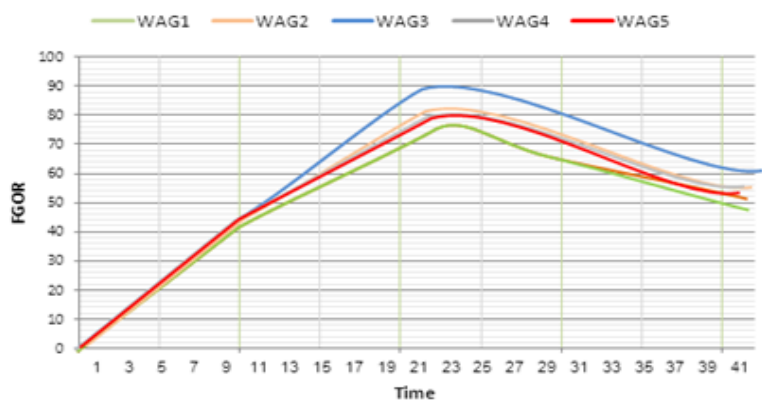

Figure 10: SWAG process.

\begin{tabular}{|c|c|c|c|c|c|}
\hline Parameter & IWAG & HWAG & SWAG & SSWAG & WAG $_{\text {aw }} \mathbf{f}$ \\
\hline Efficiency & 73000 & 76000 & 77000 & 82000 & 70000 \\
\hline FOPT & $7.7 \%$ & $7.9 \%$ & $8 \%$ & $8.5 \%$ & $7.3 \%$ \\
\hline
\end{tabular}

Table 2: Comparison of WAG methods.

\begin{tabular}{|c|c|c|c|c|}
\hline Parameter & Natural & Gas I & Water & WAG \\
\hline Daily production & $4.2 \%$ & $5.2 \%$ & $6.2 \%$ & $8 \%$ \\
\hline FOPT & 4200 & 5200 & 6200 & 8000 \\
\hline Saturation percentage & 21.7 & 21.5 & 21.4 & 20.9 \\
\hline
\end{tabular}

Table 3: Comparison of WAG and IWAG injection methods.

selected a scenario with the highest production rate. Then we compared the scenarios with highest production efficiency in each method.

We compared daily production rates in oil recovery enhancement methods. As you can see, WAG injection method offers more production rate compared with other methods. It also offers better efficiency rate and FOPT. Further, the least saturation percentage of residual oil belongs to WAG. So, this method offers better macroscopic and microscopic efficiency compared with other methods. Therefore, WAG injection method enhances final efficiency and increase oil recovery and production.

\section{Conclusion}

We studied various water and gas injection methods using Eclipse simulator and compared the results to determine the best injection scenario for the reservoir. In doing so, we investigated oil recovery rate in an under-saturated fractured reservoir in the southwest of Iran using various water and gas injection methods. Phase behavior of reservoir fluid was studied by PVTi module of Eclipse 100 (immiscible). After adjusting the history of reservoir production and pressure data, we simulated various water and gas methods based on such parameters as injection quantity and oil production rate. The following represents the summary of results:

1. The best gas injection scheme is four production wells in the sides and one injection well in the middle of the project. The best water injection scheme is four injection wells and one production well.

2. In the fractured reservoir, water injection offers higher FOE than gas injection.

3. Water injection scenario also offers acceptable results in FOPT, FPR, FGOR and FOPR. In general, water injection offers better displacement efficiency compared to gas injection.

4. Due to high permeability of reservoir rock, gas quickly reaches the production wells (gas breakthrough) and GOR increases. This 
Citation: Reza H, Arman A, Ghazal H (2016) Comparative Study on Oil Recovery Enhancement by WAG Injection Technique in a Fractured Oil Reservoir in the Southwest of Iran. J Pet Environ Biotechnol 7: 263. doi:10.4172/2157-7463.1000263

explains the lower FOPT in gas injection scenarios compared to water injection.

5. Another reason why gas injection scenario offers less oil recovery efficiency lies in field cross-slope which causes the gas to go toward higher layers and the oil of lower layers to be not swept.

6. SWAG scenario offers more water cut compared with WAG.

7. The efficiency of SWAG and WAG scenarios is almost equal.

8. SSWAG offers more efficiency compared with other WAG injection methods. This indicates that this method offers more sweeping efficiency, both microscopic and macroscopic, compared to other injection methods.

9. WAG method offers more efficiency rate and FOPT compared with natural production methods as well as water and gas injection techniques. So, this method was introduced as optimal recovery enhancement method in the field under study.

10. WAG method offers less residual oil saturation percentage. So, sweeping efficiency (microscopic and macroscopic) of this method is better than other injection methods.

11. Among various WAG injection methods in 4-point and 5-point schemes, SSWAG in 4-point scheme offers the highest efficiency and FOPT.

12. 4-point scheme offers better efficiency and less residual oil saturation percentage compared with 5-point scheme. This indicates that the increased number of production wells does not enhance efficiency and merely increases production speed. Therefore, 5-point scheme increases project costs, particularly the costs of drilling production wells.

13. The efficiency of SWAG injection method is less than SSWAG. This indicates that SWAG in single-phase offers less displacement and production efficiency compared with SSWAG.

\section{References}

1. Berge LI, Stensen JA, Crapez B, Quale EA" (2002) SWAG Injectivity Behavior Based on Siri Field Data" paper SPE 75126, presentation at the SPE/DOE Improved Oil Recovery Symposium held in Tulsa, Oklahoma U.S.A.

2. Surguchev LM, Korbal R (1992) "Screeing of WAG injection Strategies for heterogeneous Reservoirs", SPE 25075, Presented at the European Conference held in Cannes, France.
3. Esmaiel TE, Fallah S, Kruijsdijk CV (2005) "Determination of WAG Ratios and Slug Sizes Under Uncertainty in a Smart Wells Environment", Delf University SPE 93569, Presented at the 14th SPE Middle East Oil \& Gas Show and Conference, Bahrain Exhibition Center, Bahrain.

4. Algharaib M, Gharbi R, Malallah A (2007) "Parametric Investigations of Modified SWAG injection Technique", SPE 105071, Presented at the 15th SPE Middle East Oil \& Gas Show and Conference held in Bahrain International Exhibition Centre, Kingdom of Bahrain.

5. Mirkalaei SMM, Hosseini J, Masoudi R, Ataei A, Demiral B, et al. (2011) “ Investigation of Different I-WAG schemes toward Optimization of Displacement Efficiency" SPE 144891, Enhanced Oil Recovery Conference held in Kuala Lumpur, Malaysia.

6. Jiang $\mathrm{H}$, Nuryaningsih $\mathrm{L}$, Adidharma $\mathrm{H}$ (2012) "The Study of Timing of Cyclic injections in Miscible CO2 WAG" SPE 153792, Western Regional Meeting held in Bakersfield, California, U.S.A.

7. Ghaderi SM, Clarkson CR, Chen S, Kaviani D (2012) "Evaluation of Recovery Performance of Miscible Displacement and WAG Process in Tight Oil Formations" SPE 152084, Vienna, Austria.

8. Quijada MG (2005) Optimization of a $\mathrm{CO}_{2}$ flood design wasson field - west Texas, Master Of Science Thesis, Texas A\&M University, USA.

9. Cobanoglu M (2001) "A Numerical study to evaluate the use of WAG as an EOR method for oil production improvement at B. Kozluca field", Turkey, PP, SPE 72127, presentation at the SPE Asia Pacific Improved Oil Recovery Conference held in Kuala Lumpur, Malaysia.

10. Klov M, Hustod N (2003) "Experimental investigation of various methods of tertiary gas injection", PP, SPE 80579, presented at the 2003 Society of Petroleum Engineers Annual Technical Conference and Exhibition, Houston USA.

11. Instefjord R, Todnem CA (2002) "10 Years of WAG injection in Lower Brent at the Gullfaks field", PP, SPE 78344, presentation at the SPE 13th European Petroleum Conference held in Aberdeen, Scotland, U.K.

12. Shi W, Corwith J (2008) "Kuparuk MWAG project after 20 years", SPE 113933 presentation at the SPE/DOE Improved Oil Recovery Symposium held in Tulsa, Oklahoma USA.

13. Rehman T (2006) A Techno economical evaluation of miscible flooding, Dalhousie university.

14. Boerrigter PM, Van de leemput BLEC, Johan Pieters, Krijin wit, Yama JGJ (1993) Fractured Reservoir Simulation Case studies ",Koninklijike/shell E\&P laboratorium SPE/1993, Bahrain.

15. Daltaban TS, Noyola A (2002) "An investigation into the technical feasibility of gas injection into fractured CHUC reservoir in the gulf of Mexico", SPE 74357 Villahermosa, Mexico.

16. Rogers JD, Grigg RB (2000) "A literature analysis of the WAG injectivity abnormalities in the CO2 process" SPE 59329, presented at the 2000 review SPE/DOE Improved Oil Recovery symposium on held in Tulsa, Oklahoma.

17. Willhite GP (1986) "Water flooding," society of engineers, Richardson, TX. 